slight one, and we fear it is still on the increase. "Unless," said Mill, "individuality shall be able to assert itself against the yoke of public opinion, Europe, notwithstanding its noble antecedents and its professed Christianity, will tend to become another China." Prof. Müller would persuade us that our Universities are a safeguard against this catastrophe. But when China is mentioned in connection with education, examinations are suggested by an irresistible association. If, therefore, England is to escape the fate of China, it is not only encouraging to reflect that the most conspicuous modern building in Prof. Müller's own University is the new Examination Schools.

DESCRIPTION OF AN INSTRUMENT FOR EXPLORING DARK CAVITIES WHICH ARE INACCESSIBLE TO DIRECT LIGHT

$\triangle \mathrm{N}$ electric lamp has recently been proposed for $\mathrm{A}^{\mathrm{N}}$ surgical and dental operations. ${ }^{x}$ Some years ago I designed an instrument for illuminating the dark cavities of the body which would, I think, be very serviceable in connection with an electric lamp.

This instrument consists of a series of prisms arranged somewhat as in the corona employed for spectrum analysis. The accompanying woodcut will be sufficiently intelligible

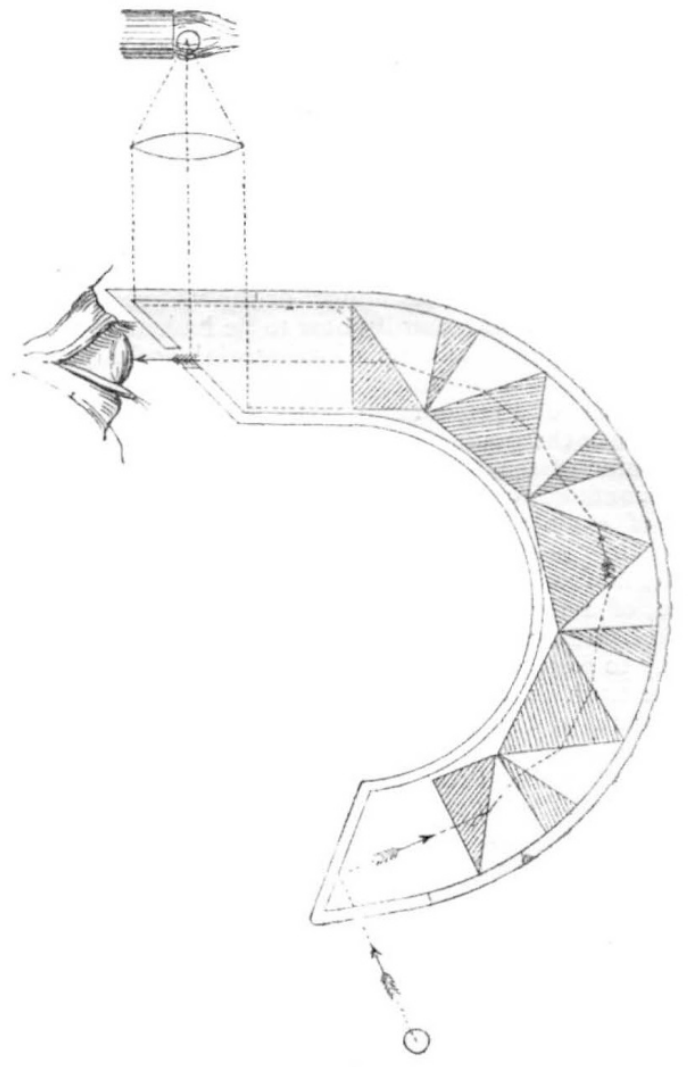

without any detailed description. The different prisms are of glass of such refractive indices as to secure achromatism, and the rays of light are bent round corners, so as, finally, to reach an external observer.

In most cases one or two such prisms will be sufficient, but any number may be employed so long as the loss of light from absorption, superficial reflection, and other causes is not so great as to defeat the object in view by destroying the distinctness of the image.

THOMAS STEVENSON

\section{IMPROVEMENTS IN BLEACHING}

A METHOD of applying the ordinary bleaching agents A (hypochlorites) in a new way has been invented by Count Dienheim de Brochocki of Paris. Instead of immersing the goods to be bleached in an ordinary "chloride of lime" vat, and subsequently souring, the inventor treats bleaching-powder with an acid and simultaneously passes air through the mixture, so that chlorine and hypochlorous acid vapours are mechanically carried off; the resulting gases are passed through an alkaline solution in such proportions as to saturate part or the whole of the alkali, or to supersaturate it at will. The resulting liquid is said to be sufficiently stable to be kept without change for two or three months; it can readily be prepared of a density of $30^{\circ}$ Beaumé, and acts as a bleacher without requiring any acidulation, and for many purposes is said to be superior to the ordinary bleaching-vat.

To this liquid the fanciful name "chlorozone" has been given, the inventor asserting that the oxidising power of a given quantity of bleaching-powder is increased by this treatment through the fixation in the product of some of the oxygen of the air used as carrying agent; the which oxygen he conceives to be liberated in the form of ozone in contact with the goods to be bleached! Although no experimental proof of the truth of this somewhat novel proposition appears to have been vouchsafed to the scientific world, yet it would seem that the new product has at least some practical advantages over the older bleaching agents, as it is used to a considerable extent in Paris, whilst works for its manufacture on a large scale have been recently erected at Warrington by Messrs. Nath. Holmes and Partners.

\section{HERING'S THEORY OF THE VISION OF LIGHT AND COLOURS ${ }^{1}$}

\section{III.}

I $\mathrm{N}$ the sixth and last memoir the author develops the part of his theory which has probably excited the most interest, namely, that of the vision of colours. He devotes his first section to the mode of classification of colours, and as this is not only the most important part, but differs materially from the generally received views, it is desirable to give its substance pretty fully.

He explains that, as he has based his general theory on what are naturally and physiologically two simple sensations, white and black, so he proposes to base his treatment of colours on the "natural system of coloursensations." He then has to seek what the simple natural sensations of colour are, neglecting in this classification all consideration of the physical properties usually connected with them. He inquires, therefore, what simple colour-sensations there are. Taking the six usually admitted, violet, blue, green, yellow, orange, and red, ho finds that two, namely, violet and orange, are obviously compound sensations; for in violet of every hue there can be distinguished clearly a mixture of the two sensations, blue and red; and similarly in orange there can always be traced the elements of red and yellow. The other four colours are red, ${ }^{2}$ green, blue, and yellow. None of the sensations known by these names contain, when pure, any semblance of another colour-sensation. These four, therefore, may with perfect correctness, as was pointed out by Leonardo da Vinci, be considered as simple or fundamental colour-sensations. On this account they have received special names, not borrowed from any coloured natural objects.

All other colour-sensations than these may be called mixed or compound sensations, as two elements can always be discovered in them; but it is a fixed principle

Continued from vol. xx. p. 639 .

2 'This, however, is not the spectral red, which contains a mixture of yellow. 